\title{
El Secreto Amor de Neruda
}

A la excelsa legión de las grandes enamoradas-Dido, Eloísa, Laura, Beatriz-parece agregarse ahora una hasta hoy desconocida de nombre aunque presente en leyenda y amor: Albertina Rosa. La presentían todos los lectores del primer Neruda-el de 20 poemas de amor y una canción desesperada, Crepusculario y Primera residencia en la tierra. En los trémulos cantos del joven poeta, alumno del Pedagógico de Santiago, en el deslumbrado peregrino de Buenos Aires, París, Ceylán y Java, hay la subyacente y pertinaz imagen de una o varias mujeres concretas de las que se apasionó Pablo. Se le atribuyeron diversas filiaciones. Tercamente se negó Neruda a develar su secreto. Ahora sabemos por qué.

Ya en Memorial de Isla Negra se vislumbró que era una muchacha de color trigueño, oriunda del propio sur de Chile.

De las mujeres que se posaron-no solo pasaron-en la vida de Neruda hay una cuya presencia inmaterial atormenta durante diez años al poeta: de 1921 a 1931, época de larvación y de asentamiento. Las otras tres determinan materialmente (en dos de los casos, también espiritualmente) su personalidad: Maruca, la javanesa; Delia, la argentina; Matilde, la chilena, ocupan considerables períodos de la peripecia estética y vivencial de Pablo: Albertina Rosa Azócar y Soto, ahora descubierta musa provinciana, era mantenida en riguroso incógnito. No la menciona siquiera en las memorias que resultaron póstumas (1974). ¿Por qué esa discreción tan acendrada si no tuvo igual para algunos de sus otros amores? Es allí, precisamente donde reside el singular prestigio de esta Beatriz araucana oriunda de Chiloé, en el boscoso y helado sur de su patria, en una isla bella y dura, poblada de leyendas coloniales y pequeños y recios mestizos republicanos, los chilotes.

Le unió a ella unatierna amistad profesional y un amor hecho de exasperación, deseo y nostalgia. La quiso tener a su costado, le propuso abandonar a su familia y su vocación para juntársele en Paris, en Ceylán, donde fuese sobre la tierra. La llamó, la invocó incansablemente, gritando versos y cartas apasionadas como aullido de perro al claro de luna. Ella lo dejó pasar, quien sabe a costa de cuanto renunciamiento. Habían sido compañeros de aula en el Pedagógico, querían ser maestros, amaban la literatura y el paisaje; estaban hechos de la misma arcilla. Sólo cuando en áspera soledad y lejanía se convenció Pablo de que era inútil esperarla, decidió casarse con Maruca, como quien se arroja a las llamas 
huyendo de la helada, para saciar la carne y el alma, la sed de amor que nunca admite sustitutos sin ella misma: A la vera de este áspero trayecto clamoroso brotaron los cuatro primeros libros de Neruda. Buscarles explicación en Sabat Escasty, Jan Neruda, Gabriela, Tagore y los ultraistas, puede significar un hermoso pero inexacto ejercicio retórico. Ahora, con la documentación humanísima en mano, lo comprobamos y sentimos. Las cartas de amor (111 poemas en prosa, quenopretendieron serlo) vienen a llenar un vacío y, como siempre, a crear otro: habrá que colmar los dos.

Ricardo Eliécer Neftalí Reyes Basualto trató en la provincia a los Azócar. Formaban estos una familia modesta católica y estudiosa. Rubén, el mayor de ellos, como Albertina Rosa y como Neruda, sería profesor, poeta y narrador: su amistad con Pablo se mantuvo inalterable. Llegó al punto de que, disintiendo en política (y la política se tragó todos los afectos en Chile, entre 1935 y 1970) no borrara el que unía a los dos amigos. Azócar era socialista; Pablo, comunista. Sospecho que, en aras de tan profunda amistad fue más lo que cedió Rubén.

Albertina Rosa era hermana de Rubén. No la consideramos de una belleza impresionante-ni Pablo buscó muñecas sino compañeras y colaboradoras, aptas para la tertulia, el mitin y la cama. Pero fue comprensiva, culta y graciosa. Y, al parecer, bastante casta: al menos supo reformarse a tiempo-o a destiempo ya que el desvelo sensual arrebataba a los dos, pese a la distancia. Una prueba de esto se halla en la forma cómo se curó del amor a Neruda. Conoció a otro poeta, delicado, hondo y feo: Angel Cruchaga Santa María, autor de Las manos juntas. Yo los vi tratarse como dos hermanos allá en nuestras jornadas literario-políticas en el inolvidable Chile del 36 al 45. Y la conocia a ella, a Albertina Rosa, compañera dulce y abnegada, dando su amistad al poeta, su novio de ayer, entonces inquieto y bohemio marido de Delia del Carril.

A mistad amorosa, entrañable, hoy puesta en evidencia a través de las cartas que, de algún modo cunsıguió el paciente y fino diplomático chileno, Sergio:Fernández $z_{i}$ Larraín, brote de las más viejas cepas de su tierra, descendiente de los fundadores de la República y familiar de ese otro gran poeta que fue Vicente García Huidobro y Fernández Concha, o sea, simplemente, de Vicente Huidobro.

Durante nuestra última estada en Madrid, (marzo-abril 1975), José Manuel Zañartu Bezanilla, director de la Editorial Rodas, puso en nuestras manos el libro: Cartas de amor de Pablo Neruda, compilación, introducción y prólogo de Sergio Fernández Larraín (Madrid: Ed.Rodas, 1975) La prensa madrileña habia recibido el volumen como un best seller: no significa una recomendación cualitativa. Quisimos enjuiciarlo por nuestros propios medios. Ha sido una empresa estimulante.

Pablo, nacido en 1904, llegó a Santiago a los dieciséis ańos para prepararse, en el Instituto Pedagógico, y titularse como profesor de francés y castellano. La primera carta enviada a Albertina Rosa no fechada, es de 1921; la última, de 1931; son datos concluyentes: Albertina Rosa fue la novia, la ilusión del poeta entre sus 17 y sus 27 años; es decir, llenó su juventud. Cuando leemos hoy sus libros póstumos $(2000, E l$ jardin en la noche, etc.) nos percatamos de que la inspiración juvenil de Neruda llega intangible a su ancianidad, y que el Canto generaly otros poemarios, escritos entre los 40 y los 60 parecen ajenos--salvo ciertos recursos retóricos--a su inspiración primordial, primigenia y vesperal. En ella se juntan la aurora y el véspero: los dos crepúsculos, el matutino y el de la tarde. Si 
esto fuera asi, habria que rectificar muchos conceptos corrientes acerca de la obra nerudiana. Por lo que me interesa, no vacilaría en certificar ese concepto.

Muchas de las cartas carecen de lugar y de fecha. Era una costumbre acronicista que practicó Gabriela Mistral toda su vida. Pablo admiraba a Gabriela, de quien fue alumno en Temuco, y ella presintió la grandeza literaria de Neruda.

La primera carta (p. 171) dice, con encantadora sencillez, evocativa de Francis Jammes y Albert Samain antes que de Jules Laforgue:

Albertina: También hoy llegó carta de ti. Está magnifica. El Domingo me voy. Venía la pluma. El viento me la quitó. ¿Ha llegado allá? He robado un gatito romano hermosísimo. Lo llevaré a Santiago. Aquí hay ya una bruma de invierno, y qué tristes los puertos cuando llueve? He aquí mi retrato.

Esta primera carta de la colección no parece la primera que escribió a Albertina Rosa. Pablo se encuentra en un puerto del Sur, tal vez en Puerto Saavedra. Quería que Albertina lo acompañase: "Venia la pluma. El viento me la quitó!"' Es curioso el estilo tan poco "nerudiano", a cambio de la sensibilidad totalmente "a lo Neruda". Dice: "llegó carta de ti'", (letter of yours, lettre de toi): no dice "tu carta" ni "carta tuya": La expresión ofrece campo a la observación. Los puntos de interrogación, de admiración, los usa sólo al final de la frase, suprimiendo los del comienzo, como en francés (o por defecto de la máquina de escribir). La nota lírica la dan la metáfora de "la pluma", y la presencia del "gato romano" y la tristeza del invierno. Neruda mezcla ya el paisaje y los seres animales y las sensaciones subjetivas. Es todo el método de 20 poemas, el del simbolismo francés: en Mallarmé y en Verlaine se encuentran las raíces de esta escuela, ya patente en Aloysius Bertrand o Lautreamont. Fernández Larraín nos ilustra diciendo que Neruda usó la máquina de escribir de Augusto Winter para aquella misiva. La segunda carta, como en un crescendo ma non troppo, aborda a Albertina de modo más concreto, sin vocativo inicial (p. 173)

Ya estaremos juntos, mocosa, y estaremos: por lo menos, más alegres. Este es un pueblo amarillo y triste, ya lo hemos recorrido entero, ya he hablado con todos mis conocidos, ya he leído todos los libros que traje, ya he visto todas las estrellas de este cielo. Por eso ve modo de escribirme, te quiero tanto cuando pienso que esta no es mi vida enteramente porque tú no estás y me faltas. El lunes me iré al campo a dos leguas, a caballo. Vendré a buscar tus cartas y a poner las que pueda escribirte que no serán muchas ni muy interesantes. No pienses que vaya a Concepción, mejor piensa, pero no creas que puedo ir: está tan lejos y no podría traerte...

El estilo ha cambiado: escribe con mayor calma, con más regodeo. La carta sigue aun, en el mismo tono calmoso, dubitativo, intenso. Ha leído todos los libros que trajo y ha visto todas las estrellas de ese cielo. ¿No es acaso un rezago de Mallarmé: "la chair est triste, hélas, et $\mathrm{j}$ 'ai lu tout les livres'? Y esas oraciones en que se usan la coma, y ya no el punto, ¿no evocan a Azorín y a Francis Jammes? Habian aparecido ya Los pueblos, La voluntad, Pomme d'anis y Claire d'Ellebense: Neruda los leyó con visible provecho: calmaron su inquietud haciéndola onda y lenta como un bostezo, como un suspiro, entre los dos. 
De las 111 cartas que componen el epistolario con Albertina Rosa Azócar, hay una docena de antología. Empero nos acucia más establecer su relación con la obra poética que paralelamente iba naciendo y que se materializa a partir de la carta No. 33 (p. 263).

Surge aquí una correlación inevitable. Pablo era muy niño cuando Gabriela Mistral llegó como directora del Liceo de Temuco, del que Pablo fue alumno entre 1910 y 1920. Es seguro que Gabriela, proveniente de una escuela de Magallanes y ya triunfante en el concurso poético organizado por 'Los Diez", embrujó al adolescente con sus versos, su actitud y sus relatos. Pablo Neruda aparece como tal, con ese nombre a partir de 1916l:| el triunfo de Gabriela se remonta a 1915. Ella, repito, venía de la helada región magallánica: él trató de ir a Magallanes, apenas le fue posible y es desde allí, desde Puerto Saavedra, desde donde estrena su epistolario con Albertina Rosa, del cual sólo tenemos acceso a las cartas de él, no a las de ella.

La simplicidad aldeana y la doble superstición del monte y el mar unen a los dos poetas, que simpatizaron y se respetaron siempre. Gabriela fue un clamor de la tierra chilena: ¿acaso no trató de serlo también Pablo? En ambos--me atrevo a decirlo--la prosa es más bella y penetrante que el verso. Los "Recados" " de Gabriela ¿no tienen como los de Santa Teresa, como los de Juan Ramón, como los de Nervo y Neruda un cierto sabor a tierra de nacer, a bumus, es decir, a insobornable humanidad y, por consiguiente, a tangible cielo? Hay más: el seudónimo Pablo Neruda aparece en noviembre de 1920, cuando ganó un certamen literario escolar; obsérvese, Neruda y Mistral, los patronímicos de dos poetas al margen de la cultura occidental ordinaria: un checo y un provenzal, dos personalidades líricas, de contenido intransferible.

Neruda escribe en una página de sus memorias, que han resultado póstumas: "la poesia es siempre un acto de paz" (Confieso que be vivido, p. 183). De esta afirmación formulada al final de su carrera se pueden inferir las conclusiones: a) la coincidencia con la bíblica serenidad de Gabriela, su directora y maestra, su zoofilia y su herbolatría: su pantésmo; b) una implícita denegatoria a la calidad poética de gran parte del Canto general, en donde, dicho sea de verdad, está ausente a menudo la poesía; c) la ratificación del amor a la mujer y a la naturaleza, reiterado en los cuatro libros póstumos y en Confieso que be vivido. Hasta donde alcanza mi percepción directa del personaje y expresión lírica, él amó la vida con fe de catecúmeno, es decir, de adolescente ávido.

Neruda llega a Santiago en marzo de 1921. Cada año, en el verano, parte de vacaciones al sur. La primera carta a Albertina Rosa está escrita en Puerto Saavedra, completamente austral. Conoció a Albertina en el Pedagógico. Ella era también del Sur. Según nos informa Jaime Larraín, don Ambrosio Azócar Peña, hombre de la clase media, casó con doña Juana Soto Rodríguez; sus hijos se llamaron Rubén, Albertina Rosa, Etelvina, Adelaida y Augusto: un ramo de copihues por el aire campestre y chileno de sus nombres.

De paso recordaremos que el padre de Neruda, don José del Carmen Reyes Morales, tuvo por mujer a doña Rosa Neftali Basualto Opazo. El nombre de Neftalí le vino por herencia materna; el de Ricardo por el paterno; el de Eliécer por los profetas a que eran tan adictos en la región. Aficiones rurales o ingenuidad o profecia: Antiguo Testamento. ¿No es acaso un perenne Cantar de los cantares de un Salomón mestizo de indio americano el 
tono caracteristico de la poesía de Mistral y de Neruda? Por eso, por primitivo esencial, aunque se doctore en arte poético, toda su poesía es un grito, una queja, un llanto, un epinicio sin matices; el único matiz, el uso del gerundio, expresión en marcha, indecisa, oteadora, en actitud de acecho como la de un cazador o un vigilante de ganados, como la de un buscador de insectos, a la hormiga y al sapo devorador de estrellas.

La nota tierna, casi pueril de estas cartas se destaca doquiera. Así, en la tercera (p. 175) dice al comenzar:

Qué cosa contarte, mi pequeña, para que te diviertas? Es de noche y estoy alegre, alegre. Estoy solo en mi casa, en mi casa que es como una torre llena de ventanas por donde miro la noche llena de estrellas. No siento cansancio del viaje a pesar de lo accidentado que fue...

El aire poético lo envuelve todo ¿Espontáneo o táctico? ¿Efluvios o red? A los dieciocho años se calcula menos, se siente más. El le cuenta a Albertina Rosa que está " junto a este brasero que me entibia, si estuvieras con tus hermosos ojos tristes, con tu silencio que tanto me gusta"'.

En este punto, antes de seguir adelante con el examen de las cartas y su relación con los primeros libros de Neruda, incidamos en dos conceptos que aparecen reiteradamente en sus Memorias, o sea en el libro final de su existencia.

1) La poesía es siempre un acto de paz. El poeta nace de la paz como el pan nace de la:harina--Los incendiarios, los guerreros, los lobos buscan al poeta para quemarlo, para matarlo, para morderlo. Un espadachín dejó a Pushkin herido de muerte entre 6 árboles de un parque sombrío. Los caballos de pólvora galoparon enloquecidos sobre el cuerpo sin vida de Petofi (Confieso que be vivido, p. 183).

2) La timidez es una condición extraña del alma, una categoria, una denuncia que se abre hacia la soledad. También es un sufrimiento inseparable como si se tienen dos epidermis y la segunda piel interior se irrita y se contrae ante la vida (Confieso que be vivido, p. 49).

Si olvidamos cualquiera de estos apuntes o conceptos habremos perdido la mejor pista para entender, apreciar, sentir y admirar al mejor Neruda, al único Neruda, a Neruda.

De paz se nutre su amor al boldo, a la cebolla, al orégano y la uva, al copihue y al salitre, al vino y al zorzal. De timidez su aislamiento, su soledad (Puerto Saavedra, Temuco, Rangoon, Isla Negra, Calcuta). Y el amor exaltado a la carne y al ensueño, desde Crepusculario hasta $E l$ jardin de la noche, no refleja otra cosa que una incontenible necesidad de compañía, de apareamiento y de entrega. Albertina Rosa, Maruca, Delia, Matilde, y las demás serán como estaciones, no de tránsito, sino de aprovisionamiento, indispensables para derrotar los incómodos fantasmas de un congénito onanismo espiritual.

La historia de este amor se desenvuelve con altibajos en el transcurso de los años 1921 a 1929, en que hace crisis, y se reanuda tristemente ya en 1931. Besa la Playa del olvido en 1932: Neruda está en Madrid. No apresuremos el relato, no lo abreviemos como un sumario periodistico. La gracia y la ejemplificación de tal pasión debe buscarse en el estilo o temple en que se desenvuelve. Difícil idioma tan puerilmente encantador." Pablo juega con su Natacha su "bonita fea", su "cucaracha", su "conejito", su "gato", su "mocosa", 
con mimos de abuelo más que con arrebatos de amante. Sus mayores reproches tendrían por causa las faltas de respuesta de ella. Empero no deja de significarle que la tiene presente en el beso y la caricia, y que la quiere tener con él. Sí, y hay que decirlo de una vez, Neruda quiere casarse con Albertina Rosa apenas llegase ella a Colombo hasta donde él le había mandado dinero para el pasaje. Ella no viajó. Más bien lo hizo a Bélgica, sin informar a Pablo, quien se lo reprocha en las cartas de la ruptura. Es entonces cuando él, cansado de su soledad, se casa y se lo comunica a Albertina Rosa. Han pasado diez años de verse esporádicamente y escribirse con irregularidad, pero con pasión por parte de él. No conocemos las cartas de ella. Las de Neruda debieron ser destruidas según expreso pedido de él a su enamorada. Ella faltó al petitorio. Las guardó en silencio mientras él anduvo por el mundo. Las publica sólo después de la muerte de él. Si causan daño ya no será a él. En cuanto a las demás, venganza refinada, que sufran el desencanto de sus falsos unicatos. Oigámosle nuevamente.

En las cartas aparecen nítidamente las amistades de Neruda y su amor a la cultura francesa. De Rubén Azócar, ("ese imasaso" ", carta 5) hay numerosas menciones, hasta el fin, cuando rompe con Albertina, a quien confiesa su preocupación por la forma como Rubén tomará aquel rompimiento. En la carta 6 (p. 189) pide a Albertina que telegrafíe a Pino. Pino no es otro que Yolando Pino Saavedra, lingüista y profesor del Pedagógico, comentador certero del estilo de Julio Herrera y Reissig. Más adelante le recomienda que persista en su amistad con Winett, la cual no es otra que Winett Anabalón, casada poco más tarde con Carlos Díaz Loyola, seudónimo del poeta Pablo de Rokha, uno de los tres grandes irreconciliables de la poesía chilena: Huidobro, de Rokha y Neruda. La obsesión de un "caracol amarillo"' (carta 10, p. 197) y de las playas solitarias aflora en Neruda; no parará hasta el último día de Isla Negra. En el saqueo idolátrico que experimenta una pequeña casa suya después de su muerte (septiembre de 1973) la estupenda colección de caracoles y botellas con barquitos dentro de ellas!, sufrió pequeño menoscabo: torpe y delictivo homenaje al poeta que solía disfrazarse de marino y hollar la arena con sus paquidérmicas y lentas pisadas insomnes. La típica casa de Isla Negra se halla intacta.

La carta 11 (probablemente de 1925, p. 201) es muy esclarecedora. Dice en ella:

Mocosa querida, mañana se irá Rubén, que va solo a buscarte, aunque sea por pocos días. Te escribiré con él mismo dándote instrucciones, mi mocosa, no creas nunca que te olvido (...) Hoy tuve una situación penosa con Rubén, le reproché duramente su mala voluntad, y le dije para determinarlo que tu viaje era forzoso por algo que no podía decirle. Aprovecha tú eso, pero dile que se trata de situaciones interiores y aun dile lo que tú quieras, siempre que ese sacrificio sirva para algo. Te abraza, te besa, Pablo (p. 201).

No cabe duda sobre el amor que unía a los dos ni de la necesidad para él de tenerla a su lado. Será el leit motiv de todas las cartas. ¿Por qué ella se rehuyó hasta provocar la ruptura ya en 1929?' ¿Y por qué guardó las cartas si no le convencían?

Las cartas 13 y 14 son literariamente extraordinarias. En la carta 18 hay un desliz encantador: "Albertina, esta carta le escribí molestándola, un poco herido por el abandono en que tiene a su Paul'" (p. 223).

Neruda estudiaba para ser profesor de francés: ahora bien ¿se refiere él a sí mismo como "Paul", en vez de Pablo, o es que Albertina le llamaba "Paul" o "mi Paul"'? Más 
parece lo último, con lo que levantaríamos una punta al velo de Tanit que pesa sobre este idilio más que epistolar. En un momento decisivo, el del rompimiento, Neruda recordará una escena de Jean Giraudoux, que en esos días (los de 1929) alcanzaba gran vigencia entre los jóvenes escritores con Suzanne et le Pacifique y otros libros.

La carta 21 (p. 228) equivale a la "canción desesperada". Debe ser de 1929: el poeta tiene 22 años. Su rebelión es ya incoercible:

Amargos han sido estos días, mi pequeña Albertina, crisis nerviosa o reunión de porquerias, ya no me aguanto solo. De noche insomnio largo, doloroso. Me desespero, me afiebro. Anoche leí dos largas novelas. Ya amanecía y aun me revolcaba en la cama como un enfermo. Aquí no me dejan dormir en las mañanas.

Mi familia: gente estúpida y mala ¿Qué soledad, Dios mío!

¿Cierto? ¿O ardid para precipitar el viaje de Albertina? Podrían coincidir ambas motivaciones. La obsesión mental, sentimental y corporal de tenerla a su lado crece en la carta 24 (p. 235). En ella le cuenta que tiene 200 pesos (suma apreciable en 1925 y 1926) "para que te vengas y para algún tiempo de pensión". Le recomienda tratar a Vicha (Vidal Oltra, casada más tarde con Manuel Eduardo Hubner), a Luz (Olguín), ambas alumnas de francés en el Pedagógico. La correspondencia oscila entre reproches a Albertina porque no responde puntualmente las cartas, proyectos de viajes, anuncio de sus primeros libros, y promesas de moderar su vida bohemia. Rubén, el hermano de Albertina, parece ser su mejor amigo. En la carta 28 anuncia tener una buena habitación en el número 330 de la calle Echaurren. Los dibujos que decoran la carta manifiestan el buen humor del poeta.

En la carta 33 (p. 253) habla concretamente de 20 poemas de amor. E1 libro más famoso, al que debió su renombre Neruda es 20 poemas de amor y una canción desesperada (1924); es también su libro más misterioso, de clave impenetrable hasta que aparecieron las Cartas de amor. ¿Por qué no quiso Pablo que nadie sorprendiera el plural secreto de aquella apasionada elegía? Hoy se ve con claridad: nunca antes. La musa, la Eloísa de aquéllos sus primeros cantos, los de sus primeros diez años de poesía, fue una sola mujer: Albertina Rosa. Y Albertina Rosa habiase casado después de que él se casó con Maruca, o al revés, poco antes, determinando con ello el apresurado e impar matrimonio de Neruda, con un amigo íntimo de éste: Angel Cruchaga Santa María, gran poeta, gran señor y gran amigo. es el recipientario de la carta de 1931 en que Pablo pide que publiquen en la revista chilena Zig Zag su casamiento con Maruca, la Javanesa. No se lo pidió a Albertina Rosa. Fue a Angel Cruchaga, lo que hace pensar que Angel era amigo ya de Albertina Rosa con quien se casaría años después.

Cuando Neruda regresa fugazmente a Santiago, llamado por la Cancillería, en 1931, busca a Albertina Rosa. Fue un encuentro sentimental, evocativo y triste. Al año siguiente parte a Madrid: todo ha terminado.

Ahora bien, obligado a referirse a la principal inspiradora de sus primeros libros, escribe Neruda, esquivando la verdad. en su Convieso que be vivido, cuya primera parte data de 1970:

Siempre me han preguntado cuál es la mujer de los 20 poemas: pregunta difícil de contestar. Las dos o tres que se enlazan en esta melancólica y ardiente poesía 
corresponden, digamos a Marisol y a Marisombra. Marisol es el idilio de la provincia encantada con inmensas estrellas nocturnas y ojos oscuros como cielo mojado de Temuco (...) Marisombra es la estudiante de la capital. Boina gris, ojos suavísimos, el constante olor a madreselva del errante amor estudiantil, el sosiego fresco de los apasionados encuentros en los escondrijos de la urbe. (Confieso... p. 71)

No concuerda enteramente esta alegoría con el relato sobre el mismo hecho que aparece en Memorial de Isla Negra(Losada, 1972); alli, en el poema "Rosaura", escribe:

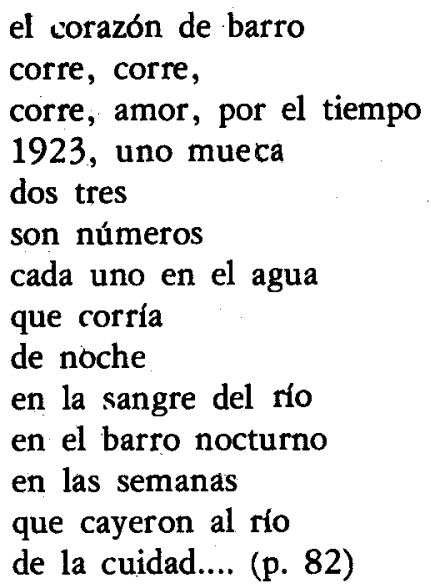

Neruda se aferraba a su secreto no sólo con misterio inquietante de poeta sino.con sobria dignidad de caballero, de hombre cabal, para quien la mujer, no por poseída, deja de ser repetable, madre en cierne, esposa potencial, novia acaso, seguramente hermana-mujer, en fin, y eso basta. Las Cartas de amor han quebrado el incógnito, mas no por indiscreción del amante, sino por incontenible revelación de ella, al borde del sepulcro de él, Pablo, en el lejano recuerdo del lírico esposo, Angel. Neruda queda así intacto, como un Boyardo del amor remoto, sans peur et sans tâcbe.

La carta 33 (p. 253) lo dice todo. No tiene fecha, pero por la secuencia de las anteriores debe ser de mayo de 1924, según se colige del texto de la carta 34. Dice la No. 33: "Estoy arreglando los originales de mi libro 20 poemas de amor y una cancion desesperada. Hay alli muchas cosas para mi Pequeria lejana. Háblame de la vida en el Pueblo. ¿Me recuerdas, mala pécora? Yo sí. También he soñado contigo suefios vagos y turbios..." En las cartas 36 y 37 confirma, en su modo infantil de entonces, que ha escrito "versos para t"' (para Albertina Rosa, que al parecer no los aprecia debidamente, y que "quiero ir a Santiago para editar un libro". La relación entre la obra de Neruda y su amor a Albertina Rosa, a Netocha, a la Pequeña fea, a la Mocosa (a quien ruega reunirsele) es evidente. Hay todavia más. En la alegre carta 36 (p. 262) llama por primera vez a Albertina Rosa “mi mujercita querida". En la 42 (p. 269) hay párrafos que no pueden ser omitidos:

¿A cómo estamos hoy? No sé. Te eseribo en la hora número 12 de la noche de vuelta del teatró. Ahora, Albertina, estarás acostada durmiendo. Tuve el 
propósito de escribirte cada día, pero ayer y anteayer (18 y 17$)$ no recibí cartas tuyas y esto apagó mi entusiasmo. Sin embargo creo te escribí una carta larga. No sé cuando (...) Me agrada tu amistad con Winett. El cliché de ese retrato lo tengo, creo, en Santiago. ¿Diste a Rubén unos versos que le prometí?

"Tenemos que arreglar nuestra vida" " ssiste en la carta 44 (p. 272). En la 45 dice que "vine a embarcarme en Valparaiso", pero sólo para ir al Sur. Desde Valparaíso, el 12 de marzo (¿1926?), se refiere a una lectura de Giraudoux. Escribirá luego a Temuco a su "queridísima lombriz" (carta 64, p. 297). Trabaja en El Mercurio (carta 66). Se dedica a remar (carta 74), pese a lo mucho que le fatiga. La carta 81 (p. 319) anuncia ya que "es inseguro mi viaje". Una de las causas de tal inseguridad sería "la fatal gira de de Rokha y Rubén, que acaban de empeñar, como último recurso, las polainas". En la 87 (p. 328) se confiesa: "Fijate, la otra noche llegué curao". La angustia es evidente. Me parece que en la 93 (p. 340) insinúase ya la ruptura. El poeta se ha fatigado ya de tantas desilusiones. La carta 95 encierra, empero, novedades. En ella dice Neruda: "Yo te quería preguntar por carta de la Luz, ¿te escribió o no esa mocosa de mierda? Cuéntame, mi linda..."

Y párrafo antes declaró: "Dilen que están en prensa mis libros Tentativa del hombre infinito y Caja de naipes y Crepusculario (p. 343). Caja de naipes no es 20 poemas, pero pudiera ser probablemente el libro Anillos, escrito en colaboración con Tomás Lago, fallecido en 1975. No se sabe más. Estamos ya en 1926. Se encuentra en Ancud con el "macaco Rubén" y con de Rokha (carta 98) En la.carta 101 (p. 350) se plantea el problema de la ausencia. La carta 102 (p. 353), sin duda de 1927, le dice a Albertina Rosa desde Colombo:

En este momento la compañía me informa que los vapores, que te digo que traen una sola clase, no tocan Marscilles ( sic: Marsella) sino que salen directamente de Londres.

Tú verás. Son los barcos más baratos, pero en caso de haber dinero (ay!) vente en cualquier barco.

Está en el Consulado de Chile en Colombo y da como dirección la Agencia de Th. Cook. Albertina Rosa no viajó. Pasaron dos años en disputas sobre el viaje. Ella visitó Bélgica, pero no viajó a Ceylán, ni a Colombo, ni a Java. Las cartas son apremiantes, dramáticas e inútiles. ¿Por qué? La carta 104 (p. 359) define el caso:

Perdóname si he trastornado un poco tu estadía autrement apacible. Esto quiere decir que con todo placer te dejo en libertad para que hagas lo que creas más cuerdo y más conveniente para tí.

Desde Ceylán, el 2 de enero de 1929 (carta 107, p. 362), le reitera su amor "locamente". Ella le ha mandado una tarjeta de Londres diciéndole: "tu silencio me inquieta". El está 'furioso, irritado"'. La carta 108 es de velados reproches:

Deseo además que destruyas las cartas originales y las cosas mías que aún tienes y me envíes los retratos que te he dado. No quiero. No quiero que ellos vayan a parar en manos de tus amigos de Concepción (estoy atormentado)... 
Adios, Albertina, para siempre. Olvídame y cree que sólo he querido tu felicidad.

Ha llegado al final del pequeño drama, un drama muy burgués, una página de opereta de la belle époque, de addio gioventú, por ejemplo. El se casa, por soledad, en Java, en diciembre de 1930 , pide a Angel Cruchaga que publique en Zig Zag el retrato de la novia y regresa a Chile. Cambia cartas con Albertina Rosa. Le dice que está casado, pero que quisiera verla. España y su tragedia cicatrizan la vieja herida. La reabre ahora el amoroso rencor de Albertina Rosa y la ausencia sin retorno de 'Paul', estudiante de francés, practicante de amor y frustrado amante.

\section{UNA PEQUEÑ A EXLORACION FACTUAL}

Hemos regresado, de visita, a Chile en junio de 1975; pocos habian leido las Cartas de amor de Neruda, aunque sus demás libros se exhibían en las vitrinas. Muchos, sí, sabían del idilio con Albertina Rosa Azócar. Julio Barrenechea, poeta y pariente de Neruda, nos refirió el 19 de junio, en su departamento de la calle Monjitas, que, una vez, en Puerto Ancud, Pablo le mostró dos o tres casas en las que habitaron juveniles amadas del período anterior a 20 poemas: La conclusión de Barrenechea, concordante con lo que se refiere en Confieso que be vivido y en Memorial de Isla Negra, es que fueron varias, quizá muchas las musas de Pablo en ese período; pero el amor entrañable fue el de Albertina Rosa. "Frente a una casa, nos cuenta Barrenechea, Pablo se detuvo y me dijo: aquí vivía la número 18 de 20 poemas." Julio es un gran poeta lírico y un gran humorista de la conversación; sin embargo, su testimonio, aunque reducible, es irrefutable.

Héctor Fuenzalida V, fino crítico, ex bibliotecario de la Universidad de Chile, nos puso en contacto indirecto (el 21 de junio) con Albertina Rosa. De esa conversación telefónica, que no pudo convertirse en encuentro personal con nosotros mismos, se desprendieron los siguientes datos: a) Las cartas de Neruda a Albertina Rosa, así como las dirigidas al poeta Angel Cruchaga Santa María, fueron prestadas por ella a un sobrino de Cruchaga, su esposo, quien las transfirió al Señor Sergio Larraín Fernández, quien las ha editado; b) Albertina Rosa se casó con Angel Cruchaga (1894-1964) en el año de 1935, o sea cuando Neruda actuaba como cónsul en Madrid; c) Albertina Rosa no cumplió con el ya trascrito encargo de Neruda de "destruir" las cartas; las guardó hasta después de la muerte de su esposo, el autor de Las manos juntas (1930); d) La familia Azócar era de tipo más bien católico (con excepción de Rubén, el autor de Las puertas y Gente en la isla). Las hermanas de Albertina Rosa se opusieron a sus amores con Neruda y, al parecer, influyeron en la negativa de viajar a Ceylán para casarse con el entonces solitario, pero sensual poeta.

Todo esto refleja un pequeño drama de tipo provinciano, con escrúpulos que Pablo podría haber calificado después de "pequeños burgueses". Inclusive la casi probada entrega total de Albertina Rosa a su amante, cuando ambos salían de la adolescencia, pese a sus perfiles exageradamente sensuales y románticos, presentan los rasgos de un diminuto drama rural propio de una pieza de Pirandello. Quizá, de una "nouvelle"' de un Francis Jammes sanguíneo y posesivo. Repetimos: el propio Neruda se jacta tenuemente de sus conquistas amorosas, de su proclividad al amor físico, contrariando así la imagen de poeta romántico de fondo y ultraísta o "nerudiano" en la forma, que por lo común se lo admita.

La obra de Neruda, como la de todo gran poeta, es absolutamentelautobiográfica. Se la ve así desde Crepusculario hasta Tentativa del hombre infinito, desde Residencia en la 
tierra hasta los Versos del capitan, desde Memorial de Isla Negra hasta Odas elementales, desde 20 poemas hasta El jardin de la noche. Pero la poesia ha sido siempre un modo de expresar lo inefable. De alli que las iras y anatemas a menudo se conviertan en prosa, aun cuando se las escriba en verso. El poeta que señaló "al odio" como un sentimiento ajeno a la poesía, no podía ser, como lo fue Neruda, sino un originalísimo e inconfundible poeta del amor, mas no del amor como una actitud idílica sino del amor como una pasión y entrega total, de carne y alma, ilusión y apareamiento, gemido y hosanna. Las Cartas a Albertina Rosa lo demuestran sin réplica. Convierten a la hasta ayer secreta amante juvenial, y poderoso impulso lírico, en una de las insignes enamoradas de la historia literaria, a través de cuya correspondencia se revela a cabalidad la raíz erótica del inolvidable autor de 20 poemas de amor y una canción desesperada.

Madrid-Lima-Santiago

LUIS ALBERTO SANCHEZ abril-junio de 1975 
